Military Technical College,

Kobry El-Kobbah,

Cairo, Egypt

\title{
AUTOMOTIVE APPLICATIONS OF ALUMINUM METAL MATRIX COMPOSITES
}

\author{
MOUSSA, M.M. ${ }^{*}$, RABEEH, B.M. ${ }^{*}$, EL-HADDAD, M.A. ** AND MOHAMED, M.Y.*
}

\begin{abstract}
The automotive industry is facing the challenge of fuel economy. Many factors contribute to fuel economy. Vehicle weight is a significant factor. One approach to vehicle weight reduction is the use of lightweight materials such as aluminum. The replacement of steel by aluminum requires a cross-section that is three times greater due to the low specific strength (strength to weight ratio) of aluminum, which makes it approximately equal in weight and rigidity to steel but of three times the cost. Thus, its use is limited in mass-production vehicles.

New aluminum metal matrix composites (Al-MMC) can be processed to the higher strength associated with steels and this reduces its thickness. The high specific strength, stiffness and the flexibility in design of fiber reinforced composite structural members enhanced their automotive applications. The objective of this work is to develop a model and analyze new fiber reinforced aluminum plates to meet the requirements for automotive applications.
\end{abstract}

\section{KEY WORDS}

Automotive ; Structure, Composite material .

\section{INTRODUCTION}

It is true that technological development depends on advances in the field of materials. Composite materials in this regard represent a giant step in the ever-constant endeavor of optimization of the materials [1].

In this study, an experimental procedure to produce steel fiber reinforced aluminum plates is developed for automotive applications using hot pressing technique. The effect of hot pressing parameters is determined, material samples are tested, and the mechanical properties of the produced materials are evaluated. The analysis for

* Egyptian Armed Forces.

** Prof. High Inst. Of Tech., Tenth of Ramadan 
designing aluminum metal matrix composite plates for vehicle body panels is studied. The replacement of conventional roof material by composite material was tried. A computer program is developed for modeling the mechanical behavior of the used material through the lamination theory. The model showed how it can be modified to meet the requirements for automotive structural applications.

\section{EXPERIMENTAL WORK}

\subsection{Hot Pressing Process}

Successive layers of properly selected steel fiber and aluminum foil were stacked to make the desired fiber volume fraction and orientation. A combination of heat and pressure causes the matrix to flow around the fibers and make a bond with the next matrix layers, enclosing and gripping the fibers in between, as shown in Fig. 1.

FelAL composites are consolidated, in this fashion, under pressure and moderately high temperature, below the aluminum melting temperature. The selected temperature and the time of residence are not high, so the barrier coating in the fiber is not necessary [2].

Aluminum metal matrix composite samples were prepared by foil-fiber-foil technique symmetrical from the center in a zero direction and four plies $\left[\mathrm{O}_{4}\right.$ to study the effect of hot pressing parameters such as hot pressing temperature $(T)$, hot pressing pressure $(\mathrm{P})$ and the holding time $(t)$, which are affecting the produced material [2].

\subsection{Effect of Hot Pressing Parameters}

Hot pressing parameters were investigated by testing different samples, which were prepared at hot pressing temperature $(\mathrm{T}) 620^{\circ} \mathrm{C}, 630^{\circ} \mathrm{C}$ and $640^{\circ} \mathrm{C}$ with different other parameters. Visual testing was made by Scanning Electron Microscopy (SEM), for finally polished and etched material samples. Another set of test samples was cut to the standard dimension [3] of flat tensile test specimens by use of wire cutting CNC machine. The tensile test was applied to these specimens in the longitudinal direction (dir. 1). Load- elongation curves were obtained for these test specimens.

The hot pressing temperature $(T)$, at which the solid state diffusion bonding between the matrix material layers, is the main effective parameter. Scanning electron microscopy (SEM) images show that the solid state diffusion process occurred at different hot pressing temperature $(T)$ and constant hot pressing pressure $(P=13 \mathrm{Mpa})$, but a complete bonding between the matrix layers occurs at $630^{\circ} \mathrm{C}$ and higher temperatures, and was limited by the matrix material melting temperature. It is clear from Fig. $2(a, b, c)$ that $\mathrm{Al}$ composite samples processed at $\mathrm{T}=620^{\circ} \mathrm{C}$ and $\mathrm{t}=1 \mathrm{hr}$ revealed a clear image with localized interface. Clear continuos localized interface established at $\mathrm{T}=630^{\circ} \mathrm{C}$ and $\mathrm{t}=1 \mathrm{hr}$. Clear thin continuous and uniform interface was established at $\mathrm{T}=640^{\circ} \mathrm{C}$ and $\mathrm{t}=1 \mathrm{hr}$.

\subsection{Results and Discussions}

The examination of samples shows that the holding time effect was sharply induced coarsened interface at $\mathrm{T}=640^{\circ} \mathrm{C}$ for $\mathrm{t}=2 \mathrm{hrs}$, as shown in Fig. 3(a) and branched thick interface at $\mathrm{T}=640^{\circ} \mathrm{C}$ at $\mathrm{t}=3 \mathrm{hrs}$. At this latest case, the fiber was almost consumed for diffusion, as shown in Fig. $3(\mathrm{~b})$. Stress-strain behavior was examined for samples 
prepared at $\mathrm{T}=640^{\circ} \mathrm{C}, \mathrm{t}=1,2,3 \mathrm{hr}, \mathrm{P}=13 \mathrm{MPa}$ compared to that of a monolithic alurninum matrix as a reference sample, as shown in Fig. $4(a, b, c, d)$ respectively. The interface has a highly induced effect on composite mechanical properties. Fig. 4(d) reveals high strength with ductility for the matrix, while the effect of emerged brittle interface was established in Fig. 4(b, c) which show low strength and ductility respectively.

\section{MODELING AND APPLICATIONS}

\subsection{Stiffness Design Criterion}

The design of most body panels is governed by stiffness requirements. The choice of an alternative material design subjected to a stiffness requirement, however, depend on the loading, the boundary conditions, and the size and curvature of each individual panel. Under service loading conditions, stiffness seems to be the most restrictive structural requirernent of body panels [4]. Thus, for a preliminary panel design, the equal stiffness requirement is usually selected as the primary performance constraint to evaluate the effectiveness of using alternative material. Of course, the objective in establishing an equal stiffness requirement among different materials is that the performance of each should meet or exceed that of origina! design. The majority of body panels, however, do not contribute significantly to the global stiffness of the vehicle as pointed out in [4] and thus their designs are governed by local or regional stiffness requirements. Body panels are usually reinforced by stiffeners and edge beams, which possess transverse stiffness several order of magnitudes higher than that of the panel. Therefore, a typical body panel assembly could be represented by one or more support-free regions. The panel stiffness, $k$, of a support-free region can be expressed as:

$$
k=\frac{p}{w}
$$

Where $p$ is the lateral load on the panel, $w$ is the maximum lateral deflection due to the load $p$. The roof panel, which was selected to study, is a roof assembly of a conventional unit-body car. As shown in Fig. $5(\mathrm{a}, \mathrm{b})$, this roof is a single-layer doublecurvature shell panel which is reinforced by two cross-bar stiffeners (roof bows) and edge beams (roof rails and header)[4]. An experimental study was carried out to measure the stiffness of produced roof panel as a baseline for comparison. A production body-in-white was utilized to obtain the experimental results so that the roof panel could be tesied in situ. The complete body structure that was anchored on a bedplate was point loaded at various points along the fore and aft centerline of the roof to locate the stiffness governing point of the roof panel. The movable loading device and dial gages were anchored along a rigid frame. As shown in Fig. 6.

Fig. 7 shows the test results of the linear elastic response of each region. As expected the stiffness governing point of each region is located near the center of the region. The middle region as shown in Fig. 7, however, is found to be the stiffness governed region, at which the maximum deflection occurred, for the entire hood panel. Since we are interested in uniform thickness panel design, the stiffness governing point (center) of this region will be used as a governing stiffness requirement for the roof material substitution design. 


\subsection{Design of Roof Panel Using AL-MMC Material}

Using the Al-MMC materials (continuous fiber reinforcement) in design of roof panel which is restricted by the regional stiffness, it is necessary to develop an analytical approach to determine the stiffness constant, $k$, for the used AL-MMC panel. Based on the lamination theory and the mechanics of composite materials $[3,5]$, a mathematical model is developed as follow :

1-calculation of lamina stiffness matrix $[Q]$ from the lamina properties where:

$$
\begin{aligned}
& Q_{11}=\frac{E_{1}}{1-v_{12} v_{21}} \\
& Q_{12}=\frac{v_{12} E_{2}}{1-v_{12} v_{21}}=Q_{21} \\
& Q_{22}=\frac{E_{2}}{1-v_{12} v_{21}}, \quad Q_{66}=\frac{1}{G_{12}}
\end{aligned}
$$

2-transformation of stiffness matrix to different ply orientations $[\bar{Q}]$ where:

$$
\begin{aligned}
& \overline{Q_{11}}=Q_{11} \cos ^{4} \theta+Q_{22} \sin ^{4} \theta+2\left(Q_{12}+2 Q_{66}\right) \sin ^{2} \theta \cos ^{2} \theta \\
& \overline{Q_{12}}=\left(Q_{11}+Q_{22}-Q_{12}\right) \sin ^{2} \theta \cos ^{2} \theta+Q_{12}\left(\cos ^{4} \theta+\sin ^{4} \theta\right) \\
& \overline{Q_{22}}=Q_{11} \sin ^{4} \theta+Q_{22} \cos ^{4} \theta+2\left(Q_{12}+2 Q_{60}\right) \sin ^{2} \theta \cos ^{2} \theta \\
& \overline{Q_{16}}=\left(Q_{11}-Q_{12}-2 Q_{65}\right) \cos ^{3} \theta \sin \theta-\left(Q_{22}-Q_{12}-2 Q_{66}\right) \cos \theta \sin ^{3} \theta \\
& \overline{Q_{26}}=\left(Q_{11}-Q_{12}-2 Q_{60}\right) \cos \theta \sin ^{3} \theta-\left(Q_{22}-Q_{12}-2 Q_{66}\right) \cos ^{3} \theta \sin \theta \\
& \overline{Q_{66}}=\left(Q_{11}+Q_{22}-2 Q_{12}-2 Q_{60}\right) \sin ^{2} \theta \cos ^{2} \theta+Q_{66}\left(\sin ^{4} \theta+\cos ^{4} \theta\right)
\end{aligned}
$$

where $\theta$ is fiber orientation angle

3-calculation of laminate stiffness matrices $[A],[B]$, and $[D]$.

$$
\begin{aligned}
& A_{i j}=\sum_{k=1}^{n}\left(\overline{Q_{i j}}\right)_{k}\left(h_{k}-h_{k-1}\right) \\
& B_{i j}=1 / 2 \sum_{k=1}^{n}\left(\overline{Q_{i j}}\right)_{k}\left(h_{k}^{2}-h_{k-1}^{2}\right) \\
& D_{i j}=1 / 3 \sum_{k=1}^{n}\left(\overline{Q_{i j}}\right)_{k}\left(h_{k}^{3}-h_{k-1}^{3}\right)
\end{aligned}
$$

4-calculation of maximum transverse deflection of laminate structure.

5-comparison between the required regional stiffness for the roof panel and the calculated one.

6 -modifying the laminate structure to meet the required stiffness for the selected roof panel.

The mathematical model was developed using the MATHCAD to carry out the previous steps. 


\subsection{Analysis of Small Transverse Defiections of Flat Laminated Panels}

Al-MMC panel is modeled as a flat rectangular plate with sides of length $a, b$ and uniform thickness $\mathrm{h}$ as shown in Fig. 8. It is assumed that the panel material is orthotropic with the material symmetry axes parallel to the $x$-y co-ordinate axes of the plate. Under in-plane loads panel properties are defined in terms of the in-plane stiffness $A_{11}, A_{12}, A_{22}, A_{66}$ as indicated by the plate load-strain relation given in $\mathrm{Eq}$. (4) where $[B]=0$. The subscripts 1,2 for the material symmetry axes now coincide with the $x-y$ plate axes, since the plate is orthotropic. Under bending loads, the panel properties are determined by the flexural rigidity matrix [D] given in Eq. (4). The stiffness properties depend on laminate structure and it is assumed that they have been determined in terms of structure materials design analysis, or alternatively by the mechanical testing of composite plate specimens with similar structure.

The panel is assumed to have simply supported edges and to be loaded by a transverse load $\mathrm{P}$, which could be concentrated at a point.

The main requirement for the design analysis of plates is to determine the maximum plate deflection and hence the plate stiffness.

Consider an orthotropic rectangular plate under flexural loading. The detailed analysis of reference [3] shows that the maximum deflection may be expressed in the general form by Eq. (5) :

$$
w=\frac{a^{4} p}{\pi^{4}\left[D_{11}-2\left(D_{12}+2 D_{66}\right)\left(\frac{a}{b}\right)^{2}+D_{22}\left(\frac{a}{b}\right)^{4}\right]}
$$

For a center point load $\mathrm{P}$, the maximum deflection is at the central loading point [6].

\subsection{Transverse Stiffness of AI-MMCs Panels}

Transverse Stiffness of Al-MMCs panels, which were hot pressed at $\mathrm{T}=640^{\circ} \mathrm{C}$ with holding time $t=1 \mathrm{hr}$ and $\mathrm{P}=13 \mathrm{MPa}$, with different orientations of orthotropy and with different values of fiber volume fractions $V_{f}$, was determined using the above mathematical model.

The transverse stiffness was calculated for different orientations of the orthotropic AlMMC plates with constant volume fraction $V_{f}=0.35$, thickness $h=1.6 \mathrm{~mm}$ and dimensions of the middle region of the tested roof panel $a=300 \mathrm{~mm}, b=800 \mathrm{~mm}$. The panel is assumed to have four plies, each of thickness $0.4 \mathrm{~mm}$. The used AL-MMC elastic moduli $E_{1}=118 \mathrm{Gpa}, \mathrm{E}_{2}=89 \mathrm{GPa}, v_{12}=0.31$ and the shear modulus $\mathrm{G}_{12}=72$ Gpa. The panel was loaded at its center by a concentrated force $P=100 \mathrm{~N}$.

Fig. 9 shows the effect of different ply orientations on the panel maximum deflection and hence panel stiffness constant $(k)$. The panel stiffness constant $(k)$ has its maximum value at the ply orientation $[0]_{4}$ since this ply orientation shows the lowest deflection.

Fig. 9 shows that the ply orientations of the used AL-MMC laminate with $[0]_{4},[0 / 30]_{2}$, $[0 / 45]_{2},[0 / 60]_{2}$ have almost equal deflections under the same lateral load and so the bending stresses in $\mathrm{x}$-direction for each were evaluated for comparison.

\section{CONCLUSION}

MMCs present some unique challenges for designers and material engineers in the automotive industry. From the materials stand point, they require a deep understanding 
of the interaction of two chemicaily different materials under extreme processing and operating conditions.

Hot pressing process parameters were investigated for producing Al-MMCs. The change in the hot pressing parameters exhibits great effect in the produced Al-MMC samples. The production process can be adapted, by controlling the hot pressing parameters, to get final produced Al-MMC material with specified mechanical properties. Hot pressing temperature, holding time and hot pressing pressure effects were studied. A continuous fine interface that was obtained at $\mathrm{T}=640^{\circ} \mathrm{C}$ for one hour holding and pressure of $13 \mathrm{MPa}$ exhibit high strength and ductility compared to others. Stress-Strain response for specimens prepared at $T=640^{\circ} \mathrm{C}$ for two or three hours holding time at pressure of $13 \mathrm{MPa}$ has lowest yield strength as a consequence of brittle interface. Al-MMCs exhibit higher strength and ductility compared to monolithic Al-matrix.

Using the Al-MMCs as a substitution material for the roof body panel, it was found that the maximum stiffness achieved by the Al-MMCs is suitable for that required for the body panel designed on the bases of the stiffness design criterion. The comparison between the stiffness of the base material and that of the substituted material shows that $k_{\text {base }}$ material $=4 \%$ while $k_{\text {composite }}=2.8 \%$.

Al-MMCs offer.a good response for designing materiais that satisfy the required stiffness for the car body panels. One way to get this material by using another Almatrix alloys which has higher modulus and/or use fiber reinforcement materiai with higher modulus. By any way there was a significant reduction of weight of roof panel produced from Al-MMCs.

The roof panel is one of the heaviest panels in the car body. In average, for a passenger car, the steel roof panel weight about $11 \mathrm{~kg}$ and it will be $78 \%$ lighter using Al-MMCs reinforced by continuos steel fibers with $V_{f}=0.35$.

\section{REFERENCES}

[1] Mel M.Schwatz, "Composite Materials Handbook", McGrow-Hill. Inc,1992.

[2] B. M. Rabeeh, M. M. Mousse, M. Y. Mohamed and M. A. EL-Haddad; "Aluminum Metal Matrix Composites in Aerospace Applications" Proceedings of 8th ASAT Conference, Paper MP-03, 1999.

[3] Ronald F. Gibson; "Principles Composite Material Mechanics", McGrow-Hill.Inc, 1996.

[4] David C. Chang, K.M.Wu, and J.R.Vella; "The Regional Stiffness Requirement of Body Panels for Material Substitution Design", SAE, 841202,1981.

[5] Karl T. Herakovich; "Mechanics of Fibrous Composite”, John Wiley \&Sons, 1998.

[6] Kouichiro Fukutomi, Manabu Maruyama, Masaru Kudo, and Tatsuo Nagamitsu; “ Verification of Finite Element Method Applied to Automotive Body Panels", SAE, 930520, 1993.

[7] M.M. Younes, M.E. Hassan, and M.M. El-Maddah. ;"Elasto-Plastic Analysis of Thin -Walled Spherical Cap Under Uniform Pressure", Technology and Armament Magazine, Volume13, July, 1997. 


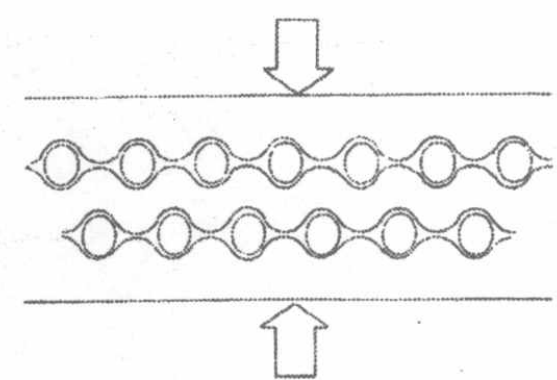

Fig. 1 Schematic of steel fiber/AL foil fabrication by diffusion bonding.

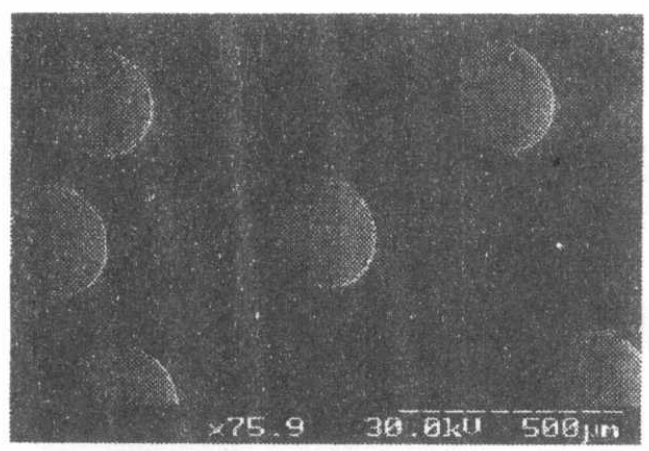

Fig. 2(a) Scanning Electron Microscopy of Aluminum Metal Matrix composite sample with steel fibers produced by hot pressing at $\mathrm{T}=620^{\circ} \mathrm{C}$ and $\mathrm{t}=1 \mathrm{hr}$.

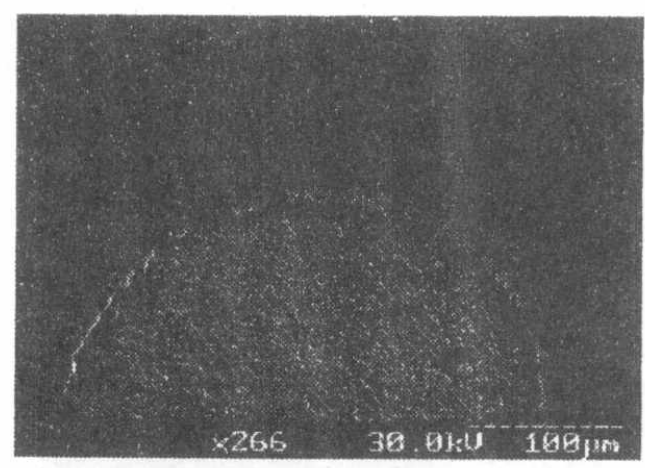

Fig. 2(b) Scanning Electron Microscopy of Aluminum Metal Matrix composite sample with steel fiber produced by hot pressing at $\mathrm{T}=630^{\circ} \mathrm{C}$ and $\mathrm{t}=1 \mathrm{hr}$. 


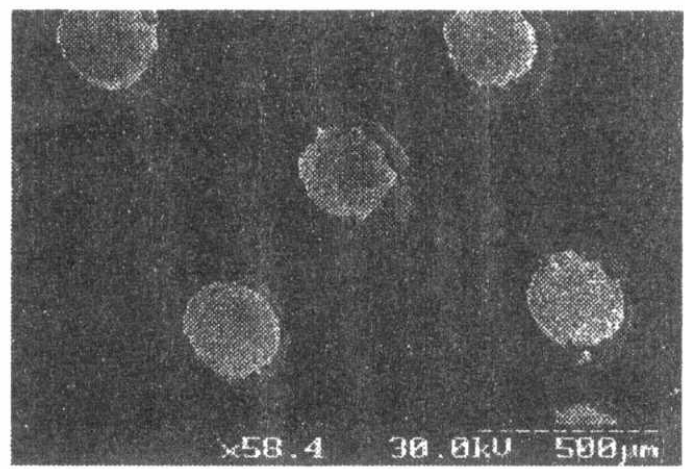

Fig. 2(c) Scanning Electron Microscopy of Aluminum Metal Matrix composite sample with steel fiber produced by hot pressing at $\mathrm{T}=640^{\circ} \mathrm{C}$ and $\mathrm{t}=1 \mathrm{hr}$.

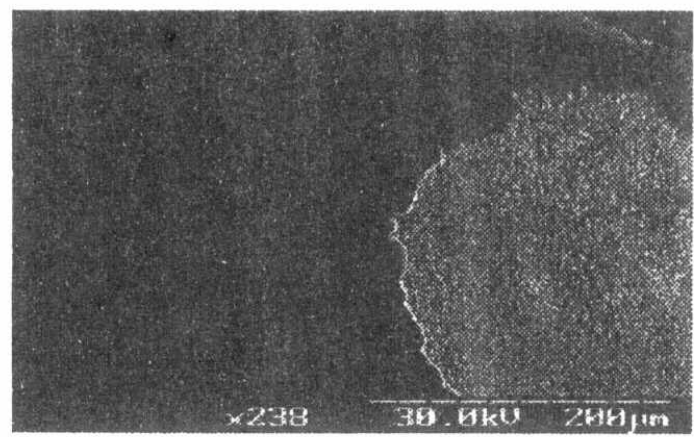

Fig.3 (a) Scanning Electron Microscopy of Aluminum Metal Matrix composite sample with steel fiber produced by hot pressing at $\mathrm{T}=640^{\circ} \mathrm{C}$ and $\mathrm{t}=2 \mathrm{hrs}$.

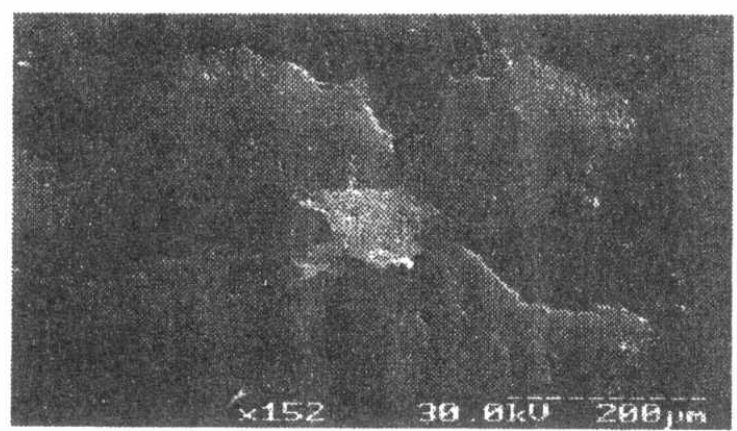

Fig.3 (b) Scanning Electron Microscopy of Aluminum Metal Matrix composite sample with steel fiber produced by hot pressing at $\mathrm{T}=640^{\circ} \mathrm{C}$ and $\mathrm{t}=3 \mathrm{hrs}$. 


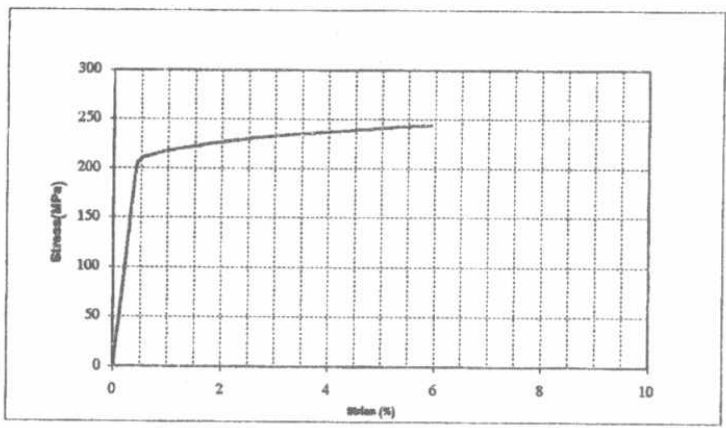

Fig. 4(a) Stress-Strain diagram of Al-MMCs prepared by hot pressing at $\mathrm{T}=640^{\circ} \mathrm{C}$, $\mathrm{t}=1 \mathrm{hr}, \mathrm{P}=13 \mathrm{MPa}$.

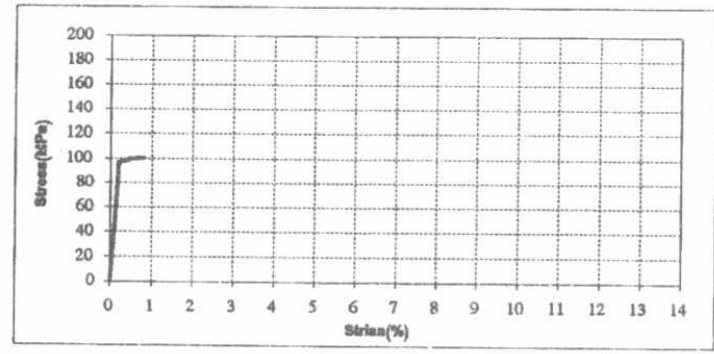

Fig. 4(b) Stress-Strain diagram of Al-MMCs prepared by hot pressing at $\mathrm{T}=640^{\circ} \mathrm{C}$, $\mathrm{t}=2 \mathrm{hr}, \mathrm{P}=13 \mathrm{MPa}$.

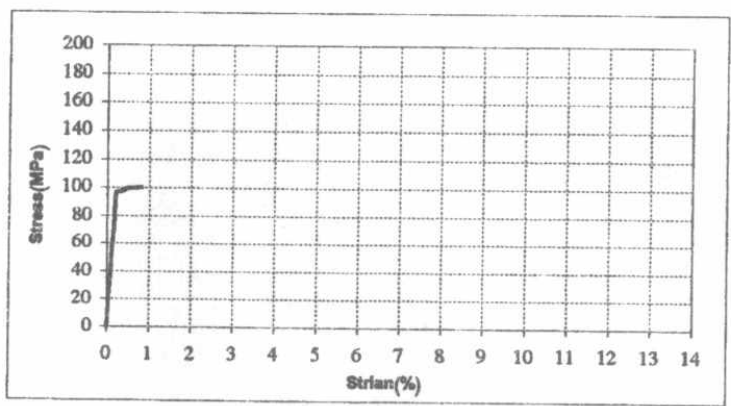

Fig. 4(c) Stress-Strain diagram of Al-MMCs prepared by hot pressing at $\mathrm{T}=640^{\circ} \mathrm{C}$, $\mathrm{t}=3 \mathrm{hr}, \mathrm{P}=13 \mathrm{MPa}$. 


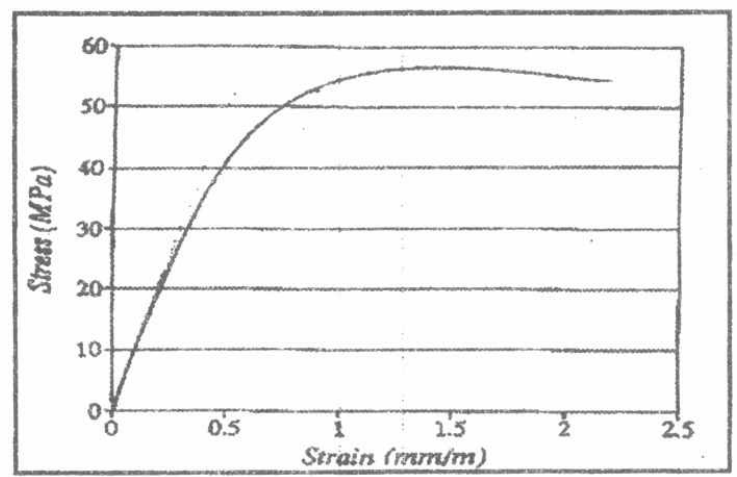

Fig.4 (d) Stress-Strain diagram of monolithic matrix of Aluminum [7]

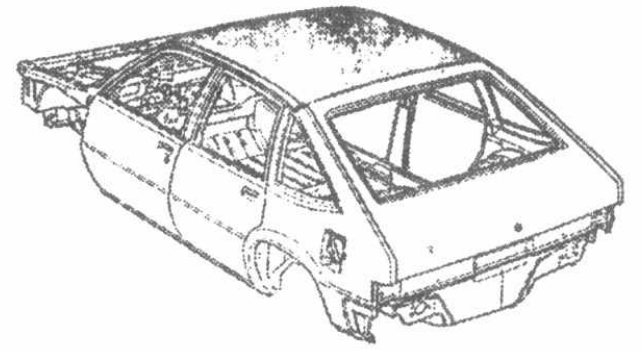

Fig. 5 (a) Roof panel of a hatchback 4-door compact car. [4]

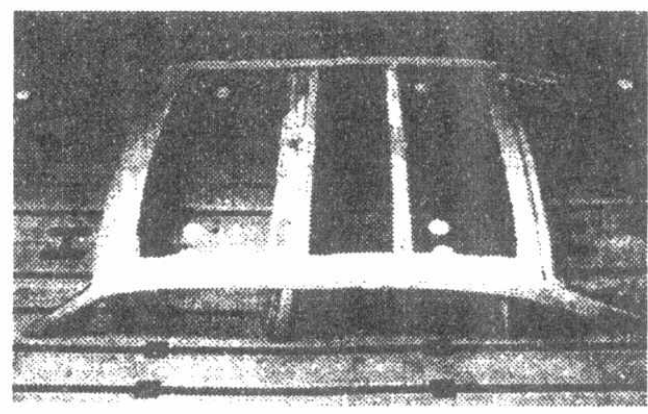

Fig. 5(b) Reinforcement for the roof panel. [4] 


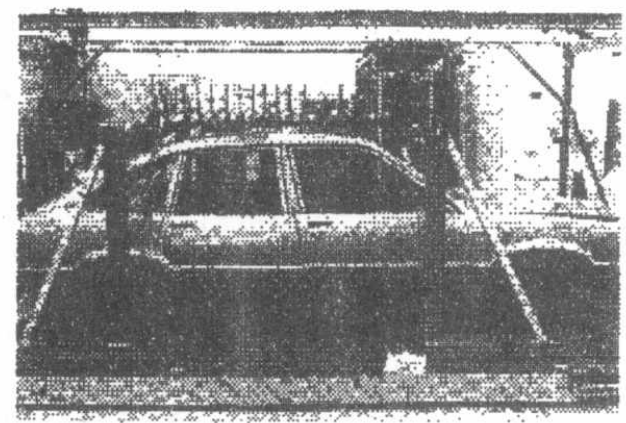

Fig. 6Roof panel test set-up. [4]

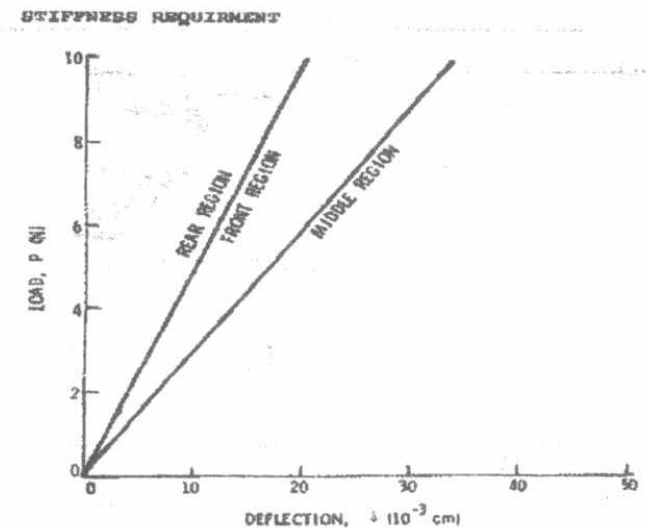

Fig.7 Linear elastic response of the roof panel experimental results. [4]

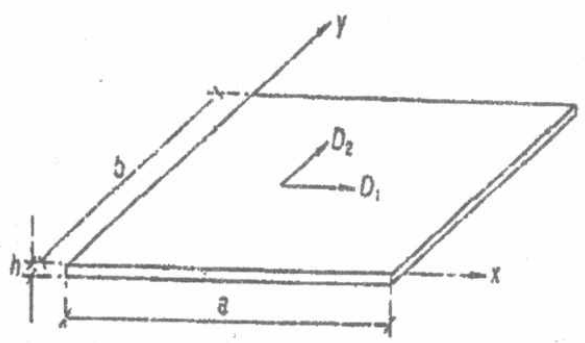

Fig. 8 Orthotropic plate geometry. 


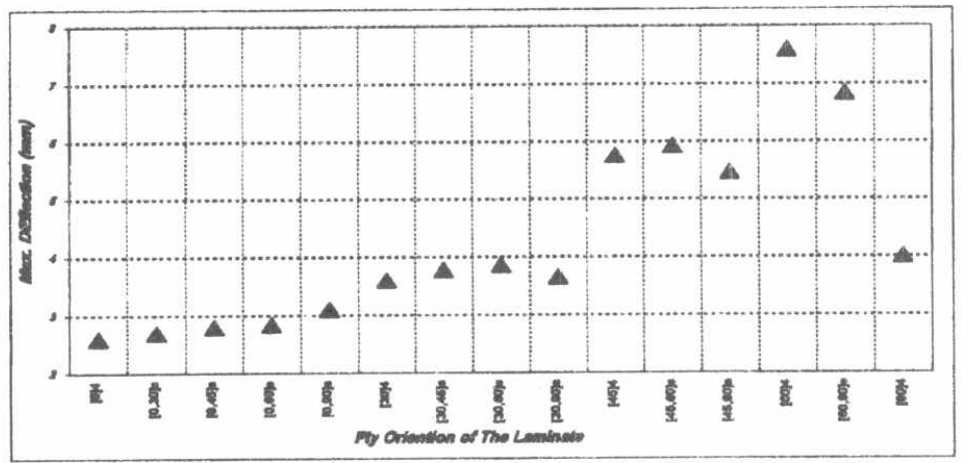

Fig.9 Effect of different ply orientation on the panel lateral deflection.

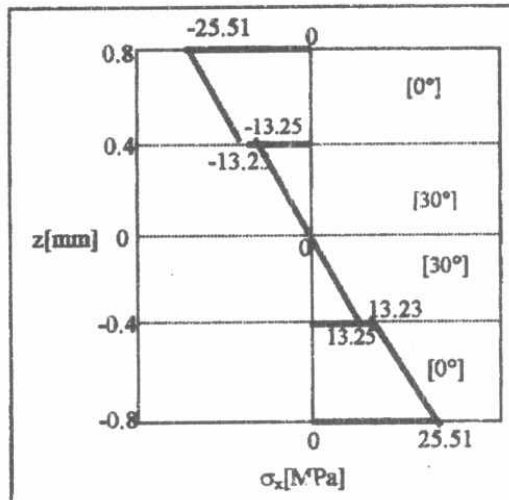

(a)

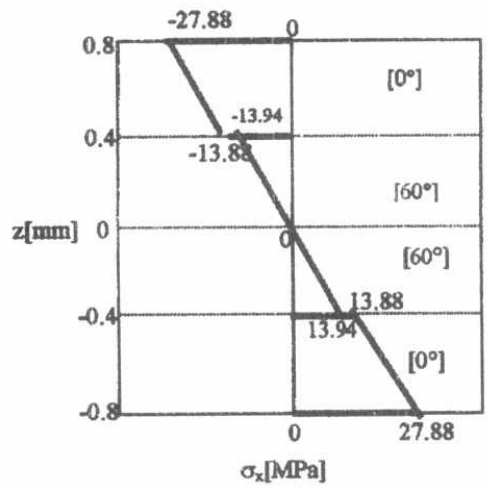

(c)

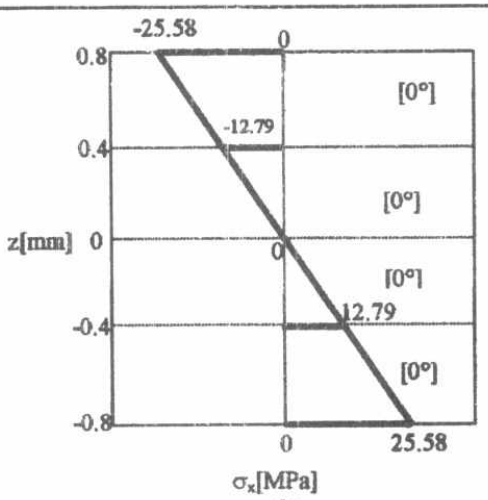

(b)

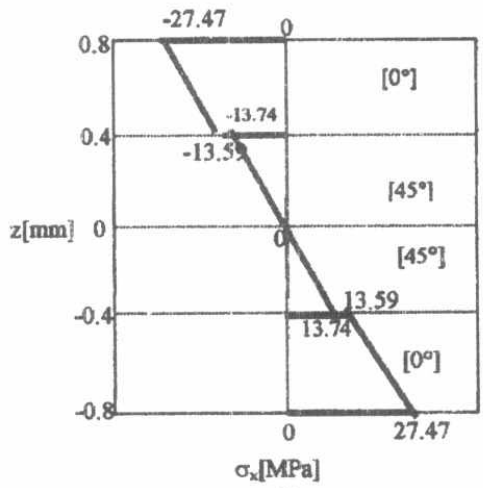

(d)

Fig. 10 Bending Stress distribution along the panel. 